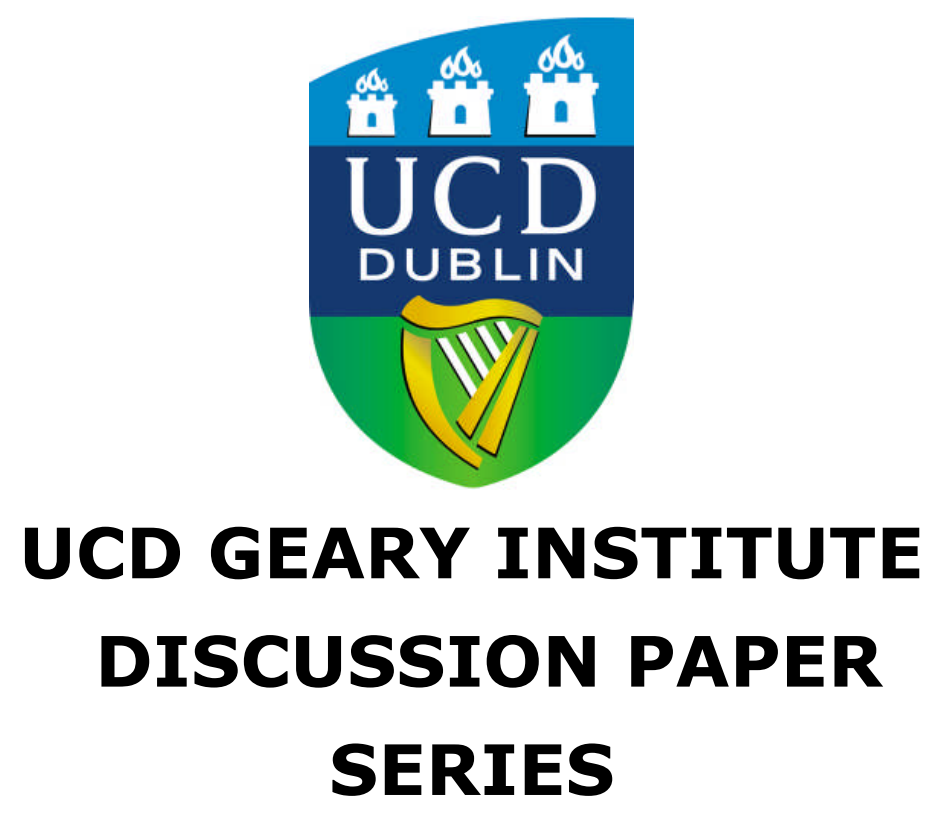

Mode of Context Effects in Measuring Household Assets 


\title{
Mode and Context Effects in Measuring Household Assets ${ }^{1}$
}

\author{
Arthur van Soest, Netspar, Tilburg University and RAND ${ }^{2}$
}

\author{
Arie Kapteyn, RAND ${ }^{3}$
}

February 2009

\begin{abstract}
Differences in answers in Internet and traditional surveys can be due to selection, mode, or context effects. We exploit unique experimental data to analyze mode and context effects controlling for arbitrary selection. The Health and Retirement Study (HRS) surveys a random sample of the US 50+ population, with CAPI or CATI core interviews once every two years. In 2003 and 2005, random samples were drawn from HRS respondents in 2002 and 2004 willing and able to participate in an Internet interview. Comparing core and Internet survey answers of the same people, we analyze mode and context effects, controlling for selection. We focus on household assets, for which mode effects in Internet surveys have rarely been studied. We find some large differences between the first Internet survey and the other three surveys which we interpret as a context and question wording effect rather than a pure mode effect.
\end{abstract}

JEL codes: C42, C81, C93

Keywords: Internet surveys, CAPI, CATI, portfolio choice

${ }^{1}$ This research was funded by the NIA. We are grateful to participants of the

RAND/University of Michigan Internet Project meetings and the Social Research and the Internet conferences in Mannheim for useful comments.

2 Tilburg University, P.O. Box 90153, 5000 LE Tilburg, The Netherlands, email avas@uvt.nl

${ }^{3}$ RAND Corporation, 1776 Main Street, Santa Monica, 90401-3208, U.S.A., email Kapteyn@,rand.org 


\section{Introduction}

Differences between the distribution of answers given to the same survey question in an Internet survey and a survey using a traditional mode like computer assisted personal interviews (CAPI) or computer assisted telephone interviews (CATI) can be due to selection effects or to mode or context effects. Selection effects arise when the Internet sample and the CAPI/CATI sample are not representative for the same population of interest. A general concern with Internet interviewing is that, even if the initial sample is a probability sample that is representative of the population of interest, households without Internet access are not covered. Since these households are in many respects not a random subpopulation, this may lead to serious selection effects. See Best et al. (2001), Berrens et al. (2003) and Denscombe (2006) for some specific examples.

One solution to this specific selection problem is to provide Internet access (and the necessary equipment) to those who do not yet have it so that they can participate in the same way as those who already had Internet access (see, e.g., Fricker and Schonlau, 2002). This is the solution used by, for example, Knowledge Networks and the American Life Panel in the US and the CentERpanel and the LISS panel in the Netherlands. It is an attractive solution but it is costly - providing a personal computer and Internet access is not cheap. Moreover, even when offered for free, specific groups like the elderly may still be reluctant to participate, leading to another selection problem due to an increase in unit non-response.

General socio-economic surveys like the Panel Study of Income Dynamics (PSID) or the Health and Retirement Study (HRS) in the US and the European Social Survey (ESS) or the Survey of Health, Ageing and Retirement in Europe (SHARE) are traditionally administered using face-tot-face (CAPI) or telephone (CAPI) interviews. To reduce the costs of these surveys, it has been suggested to replace the CAPI or CATI interview by an interview over the Internet for respondents who have access to the Internet (and are willing to participate in an Internet interview rather than a telephone or face-to-face interview). Since Internet interviews are generally much cheaper than CAPI or CATI 
interviews, this may lead to improved cost efficiency. An important concern, however, is whether the change in interview mode does not affect the survey answers. In other words, this is a feasible solution if there are no mode effects. Even if Internet answers would in some sense be better than CAPI or CATI answers (because of, for example, a reduction in social desirability bias or other interviewer effects), the mixed mode nature of the data would lead to complications for the analysis.

Pure mode effects arise when the same survey questions are asked in the same context to the (random samples of) the same population, with different answers. An example could be an interviewer effect such as social desirability - leading to differences in answers to the same question depending on whether or not an interviewer is present. As explained by Dillman and Christian (2005), a change of interview mode is very often accompanied by a change in question wording, question layout, or question context (e.g., a change in the preceding questions; cf. Schwarz, 1996). Mode effects in a broader sense also refer to the wording, layout and context effects that are due to inevitable changes in wording, layout or context that go together with a change in mode. For example, the fact that answers in an Internet survey depend on layout (see, e.g., Christian and Dillman, 2004) whereas layout plays no role in telephone or face-to-face interviews already implies that the effect of layout and a pure mode effect cannot be disentangled. On the other hand, the conceptual distinction between mode effects and selection effects seems much clearer, and the main goal of our analysis is to analyze mode effects in a broad sense for the population with Internet access, controlling for selection effects.

While existing studies have looked at mode effects in Internet surveys, most of these have done this under restrictive assumptions about the nature of sample selection effects. The reason is that the Internet survey and the traditional survey typically use separate independent samples, implying that mode effects and selection effects are hard to disentangle. In the ideal experiment on mode effects, the same questionnaire would be 
administered to the same respondents both over the Internet and using a traditional interview mode. ${ }^{4}$

In this study, we exploit the unique nature of the HRS Internet experiment carried out by RAND and the University of Michigan to analyze mode and context effects while controlling for selection affects, without making any assumptions about the nature of the selection process. In this experiment, the same respondents got CAPI or CATI interviews and Internet interviews, allowing us to control for selection effects by focusing on the same groups of respondents. The Internet survey questions and the CAPI/CATI questions overlapped, but the questionnaires were not identical, implying that context effects may play a role, in addition to pure mode effects. Moreover, there were slight differences in the wordings of the questions. By looking at several waves of data we can say something about the importance of these effects versus pure mode effects. We focus on two economic variables, in particular ownership and amounts invested in two important types of household assets (checking and saving accounts and stocks and stock mutual funds). Measuring the size and composition of household wealth is important for many economic and multi-disciplinary analyses, ${ }^{5}$ while at the same time reporting asset amounts is known to be a demanding task for the respondents.

We have two waves of core HRS interviews, each of them followed by an Internet interview. For the first wave, we find large differences between the Internet answers and the core answers both in ownership and in amounts held. For the second wave, however, these differences almost completely disappear, and the Internet results for the second wave are very well in line with both CAPI/CATI interviews. Our interpretation of these findings is that there is no evidence of pure mode effects, but seemingly small changes in question wordings combined with questionnaire context - what is the complete set of asset types considered in the survey - have a large effect on the answers, leading to a

\footnotetext{
${ }^{4}$ In principle there may also be mode effects between CAPI and CATI. We do not pay any attention to these in the current study and essentially consider CAPI and CATI as the same mode.

${ }^{5}$ See, for example, Guiso, Haliassos and Jappelli (2002).
} 
strong bias in the first Internet survey. This is not a pure mode effect but the combination of a context effect with a specific wording of the questions.

The remainder of this paper is organized as follows. Section 2 describes the design of the HRS Internet experiment and provides detailed wordings of the main survey questions in our analysis. In section 3 we describe ownership of the two types of assets we consider. In section 4 we look at amounts held for those who report ownership. Section 5 summarizes the results of some regressions controlling for observed background characteristics. Section 6 concludes.

\section{The HRS Internet Experiment}

The Health and Retirement Study (HRS) is a stratified random sample of the US population ages 50 and older and their spouses, interviewed once every two years since 1992, with regular refreshments. In the years without core interviews, subsamples are often asked to participate in specific modules, usually administered by mail. We use the interviews in 2002 and 2004 (a mix of CAPI and CATI). For the purpose of the Internet experiment, these interviews contained a module with questions on Internet access and willingness to participate in an Internet interview in between the biennial core interviews. ${ }^{6}$

The first relevant question for our purposes was:

Do you regularly use the World Wide Web, or the Internet, for sending and receiving e-mail or for any other purpose, such as making purchases, searching for information, or making travel reservations?

Those who answered "yes" to this question were then asked:

\footnotetext{
${ }^{6}$ This module was not administered to proxy respondents - used for those unable to respond for themselves because of physical or mental limitations.
} 
We may want to try out a procedure for asking questions of some of the participants in this study, using the Internet. Would you be willing to consider answering questions on the Internet, if it took about $15 \mathrm{~min}$ of your time?

Those who also said "yes" to this question were considered eligible for the Internet survey and a random subset of them were sent a mailed invitation to participate. They got a URL for the survey with an ID and password. A \$20 check was enclosed with the invitation letter. Up to three reminder letters were sent to those who were invited but did not $\log$ in to start the survey and to those who started but did not complete. Couper et al. (2007) describe the data collection of the first wave and analyze the various steps in the selection process. Schonlau et al. (2009) analyze selection effects and whether it is possible to correct for these by conditioning on a limited set of background variables.

The Internet interviews were launched in 2003 and early 2006, including many questions that were also in the core 2002 and 2004 HRS interviews, as well as specific experimental modules designed for Internet interviewing. Overall, the Internet interviews were much shorter than the core interviews, with, for example, questions on only three types of household assets, much less than in the core interviews. The two Internet questionnaires were also quite different. The first one (2003) focused on Internet and computer use, health problems, disability and work limitations, numeracy items, psychosocial items, expectations, and questions about household assets (housing, checking and saving accounts, and stocks). The second Internet interview (2006) focused on Internet and computer use, health and emotional problems, prescription drugs, social security expectations, and the same household assets.

We will consider respondents to the core surveys in 2002 and 2004 and the Internet surveys in 2003 and 2006, which are subsamples of the 2002 and 2004 core respondent samples, respectively. Due to the panel nature of the HRS with attrition and refreshment, there is a large subsample of 2002 HRS core respondents who also participated in HRS 2004, and there is also some overlap between the two Internet samples. This allows for some test - retest consistency checks to compare the quality of the data collected over the 
Internet with the data collected in the core CAPI or CATI interviews. We use the RAND version of HRS 2002, with 18,190 respondents. HRS Internet 2003 has 2,124 respondents. ${ }^{7}$ HRS Internet 2006 was drawn from the subsample of HRS 2004 with Internet access. Our HRS Internet 2006 sample has 1,301 observations out of the 20,161 observations in the RAND version of HRS $2004 .{ }^{8}$ The intersection of the four samples has 631 respondents. ${ }^{9}$

\section{Asset Questions}

We present details of the question wordings, since, as we will argue below, we think the question wording may have an important effect on the answers.

\section{HRS Core Interviews}

In the core interviews of HRS 2002 and 2004, financial respondents (i.e., the household member who is most knowledgeable about financial matters) answered a series of questions on household assets, starting with the introduction:

Savings and investments are an important part of family finances. The next questions ask about a number of different kinds of savings or investments you may have.

They then first got questions on real estate (other than main home), business or farm assets, IRAs or KEOGHs (tax-favoured retirement savings), before they got the following questions on stocks:

\footnotetext{
${ }^{7}$ About 800 randomly chosen HRS 2002 respondents with Internet access and willing to participate in an Internet interview were not interviewed for HRS Internet 2003. This was done to be able to gauge possible effects of the Internet interview on subsequent response rates to core HRS interviews.

${ }^{8}$ A second subset of HRS 2004 respondents with Internet access was interviewed over the Internet in late 2006 (HRS Internet 2006, phase 2), with a questionnaire that differed from the one used in the early 2006 Internet interviews (first phase). The second phase data are not used for our analysis.

${ }^{9}$ Many of the HRS Internet 2003 respondents are included in the second phase subsample referred to in the previous footnote. They could not be interviewed yet because of crowding out of the regular HRS 2006 interviews.
} 
(Aside from anything you have already told me about,) Do you (or your [husband/wife/partner]) have any shares of stock or stock mutual funds?

Respondents who answered affirmatively immediately got a follow-up question on amounts:

If you sold all those and paid off anything you owed on them, about how much would you have?

Respondents who did not provide an amount ("don't know" or "refuse") got a series of unfolding bracket questions of the form

Does it amount to less than $\$ \_$_ more than $\$ \_$_ or what?

After the questions on stocks, respondents were asked about bonds, and then came to a similar set of questions on checking and saving accounts:

(Aside from anything you have already told me about,) Do you (or your

[husband/wife/partner]) have any checking or savings accounts or money market funds?

If "yes":

If you added up all such accounts, about how much would they amount to right now?

If "don't know" or "refuse":

Does it amount to less than $\$ \_$, more than $\$ \_$, or what?

\section{HRS Internet 2003}

In the HRS Internet interviews, only three types of assets were considered. The series of asset questions started with the introduction

Next we would like to ask some questions about housing, checking accounts, and stocks. 
After the questions on housing, ${ }^{10}$ respondents then got the following questions on checking and saving accounts and stocks or stock mutual funds, with unfolding brackets for those who did not provide an amount:

Do you have any checking or savings accounts or money market funds?

If "yes":

If you added up all the checking and savings accounts and money market funds, about how much would they amount to right now?

Do you have any shares of stock or stock mutual funds?

If "yes":

If you sold all those and paid off anything you owed on them, about how much would you have?

These questions are virtually identical to those in the core interviews, but they were not surrounded by similar questions on other types of assets.

\section{HRS Internet 2006}

In the second Internet interview, we added a sentence asking the respondents explicitly not to include some other assets that may seem similar to the ones in the questions and that are not asked about separately in the Internet surveys. The questions on ownership and amounts of checking and saving accounts were therefore rephrased as follows:

Do you have any checking or savings accounts or money market funds? Please note: this does not include: Individual retirement accounts (IRAs and KEOGHs), shares of stock and stock mutual funds, corporate bonds, CDs, government saving bonds, treasury bills, or other assets.

${ }^{10} \mathrm{~A}$ similar analysis to the one we present was done for housing, for which we found no evidence of context or mode effects once selection was controlled for. To save space, these results are not presented. 
IF "yes" then:

If you added up all the checking and savings accounts and money market funds, about how much would they amount to right now? Please note: this does not include: Individual retirement accounts (IRAs and KEOGHs), shares of stock and stock mutual funds, corporate bonds, CDs, government saving bonds, treasury bills, or other assets.

Moreover, some questions on changes since the previous (core 2004) interview were added:

Do you have more or less money in (all) your checking or saving accounts or money market funds than at the time of the HRS interview in 2004?

1. had no checking or saving accounts or money market funds

2. more than in 2004

3. less than in 2004

4. about the same

If "more than in 2004" or "less than in 2004":

How much [more/less] than in 2004?

The series for stocks and stock mutual funds was very similar:

Do you have any shares of stock or stock mutual funds? Please note: this does not include: Individual retirement accounts (IRAs and KEOGHs), checking and saving accounts or money market funds, corporate bonds, CDs, government saving bonds, treasury bills, or other assets.

If "yes" then:

If you sold all those and paid off anything you owed on them, about how much would you have? Please note: this does not include: Individual retirement accounts (IRAs and KEOGHs), checking and saving accounts or money market 
funds, corporate bonds, CDs, government saving bonds, treasury bills, or other assets.

Did you buy or sell stocks or stock mutual funds since the time of the HRS interview in 2004 ?

1. yes, I bought and sold stocks or stock mutual funds

2. yes, I bought stocks or stock mutual funds

3. yes, I sold stocks or stock mutual funds

4. no - nothing bought or sold

If "yes":

Considering the total value of all your stocks and stock mutual funds, do you think it is more than, less than, or about the same as at the time of the HRS interview in 2004 ?

1. had no stocks or stock mutual funds at that time

2. more than in 2004

3. less than in 2004

4. about the same

If "more than in 2004" or "less than in 2004":

How much [more/less] than in 2004?

\section{Asset Ownership}

Table 1 gives ownership rates for checking and saving accounts. Rows refer to time and mode of measurement, while columns refer to subsamples of respondents participating in any interview (column 1) or separately in each interview (columns $2-5$ ). The first column shows that the "raw" ownership rates in the Internet interviews are substantially higher than in the core HRS interviews. Columns 3 and 5 demonstrate that this is mainly due to selection. For example, HRS 2004 gives an ownership rate of 0.856 , but if we consider the HRS 2004 ownership rate among the subsample of HRS Internet 2006 
respondents, ${ }^{11}$ this rises to 0.967 , which is actually higher than the ownership rate of 0.925 in the 2006 HRS Internet interview among the same households. Similarly, if we restrict the HRS 2002 sample to those who participated in HRS Internet 2003, the HRS 2002 ownership rate rises from 0.875 to 0.957 , close to the 0.979 ownership rate in HRS Internet 2003. We can therefore conclude that once selection effects are taken out by considering the same respondents in different interviews, the differences between the four measurements are small. The selection effects are in line with the results of Schonlau et al. (2009) who find that, in general, Internet users are healthier and in better economic circumstances.

\section{Table 1. Ownership Checking and Saving Accounts}

\begin{tabular}{|c|c|c|c|c|c|c|c|c|c|c|c|}
\hline & Sample & All & & In & RSO 02 & In & to 3 & In $\mathrm{F}$ & RSO 04 & In & nto 6 \\
\hline Var & $a b l e$ & Obs & Own & Obs & $\div$ Own & Obs & Own & Obs & Own & Obs & \%Own \\
\hline HRS & 2002 & 18093 & 85.7 & 18093 & 85.7 & 2048 & 95.7 & 15409 & 86.2 & 961 & 94.9 \\
\hline Int & 2003 & 2102 & 97.9 & 2048 & 97.9 & 2102 & 97.9 & 2035 & 97.8 & 618 & O० \\
\hline HRS & 2004 & 19771 & 85.6 & 15409 & 86.5 & 2035 & 96.3 & 19771 & 85.6 & 1283 & 96 \\
\hline Int & 2006 & 1288 & 92.5 & 961 & 92.7 & 618 & 92.6 & 1283 & 92.5 & 1288 & \\
\hline
\end{tabular}

Notes: Unweighted ownership rates in $\%$ (\%Own) with underlying number of observations. All: all respondents interviewed in the given wave (who answer yes or no); In HRS02: only respondents who were interviewed in HRS 2002 and answered yes or no to the ownership question. In Int03: same but only those with an answer in HRS Internet 2003; In HRS04 and In Int06: same for HRS 2004 and HRS Internet 2006.

Table 2 presents the ownership rates for stocks. Selection effects again play a large role. For example, restricting the HRS 2002 sample to HRS Internet 2003 respondents raises the ownership rate from 0.320 to 0.525 . But this is still much lower than the ownership rate for the same respondents in HRS Internet 2003, which is 0.732 . The large difference between the HRS Internet ownership rate and the core HRS 2002 rate for the same

${ }^{11}$ The number of don't know or refuse answers on the ownership questions is very small, and the ownership rates are not sensitive to including or excluding respondents who gave such an answer in another wave. What matters is if they participated in the (Internet) interview as a whole. 
households $(0.732-0.525)$ is one of the puzzling findings of the $2002-2003$ comparison. Looking at it in isolation, it could be due to an interview mode effect or a context effect or both.

Comparing HRS 2004 and HRS Internet 2006 does not give the same discrepancy. The selection effect is similar (a rise from 0.309 to 0.492 ) but once selection is controlled for, the ownership rates in HRS 2004 and HRS Internet 2006 are very similar (0.492 and 0.479). This suggests that stock ownership reported in HRS Internet 2003 is an outlier. An explanation may be the difference in context and question wording. Since in HRS Internet 2003 there were no questions on related assets (like IRAS invested in stocks or stock mutual funds), respondents may have categorized related assets as stocks and stock mutual funds. Explicitly excluding these assets by rephrasing the question as was done in the HRS Internet 2006 interview solves this problem and removes the context effect. ${ }^{12}$

\section{Table 2. Ownership Shares of Stock and Stock Mutual Funds}

\begin{tabular}{|c|c|c|c|c|c|c|c|c|c|c|}
\hline Sample & All & & In & RSO 02 & In & to 3 & In $\mathrm{F}$ & R.SO 04 & In & nto 6 \\
\hline Variable & Obs & ○Own & Obs & $\div$ Own & Obs & \%Own & Obs & $\%$ Own & Obs & Own \\
\hline HRS 2002 & 18025 & 32.0 & 18025 & 32.0 & 2042 & 52.5 & 15311 & 32.9 & 949 & 53.3 \\
\hline Int 2003 & 2099 & 73.1 & 2042 & 73.2 & 2099 & 73.1 & 2025 & 73.1 & 611 & 76.3 \\
\hline HRS 2004 & 19697 & 30.9 & 15311 & 31.8 & 2025 & 53.3 & 19697 & 30.9 & 1261 & 49.2 \\
\hline Int 2006 & 1272 & 47.9 & 949 & 49.2 & 611 & 52.0 & 1261 & 47.7 & 1272 & 47.9 \\
\hline
\end{tabular}

Notes: See Table 1

Table 3 presents transitions in ownership of stocks for the four waves, always using all the available observations (i.e., using the unbalanced panel). For all pairs of waves, there is a strong (and statistically significant) positive relation between owning stocks in the two waves. There are some substantial differences between the transition rates. For example, the transition rates from ownership in HRS 2002 to non-ownership in 2004 are

${ }^{12}$ An alternative explanation might be a macro-economic trend leading to a genuine peak in ownership of stocks and stock mutual funds in 2003, but this seems implausible given the historical trend in stock returns in the past decade. 
much higher than the transition rates from HRS 2002 to HRS Internet 2006. Table 3, however, does not make clear which part of this is a selection effect, due to a different sample composition used for the HRS 2002 - HRS 2004 transitions (no selection at all on Internet access) and all others (selection on Internet access at least once).

Table 3. Transitions in Stock Ownership - Unbalanced Panel

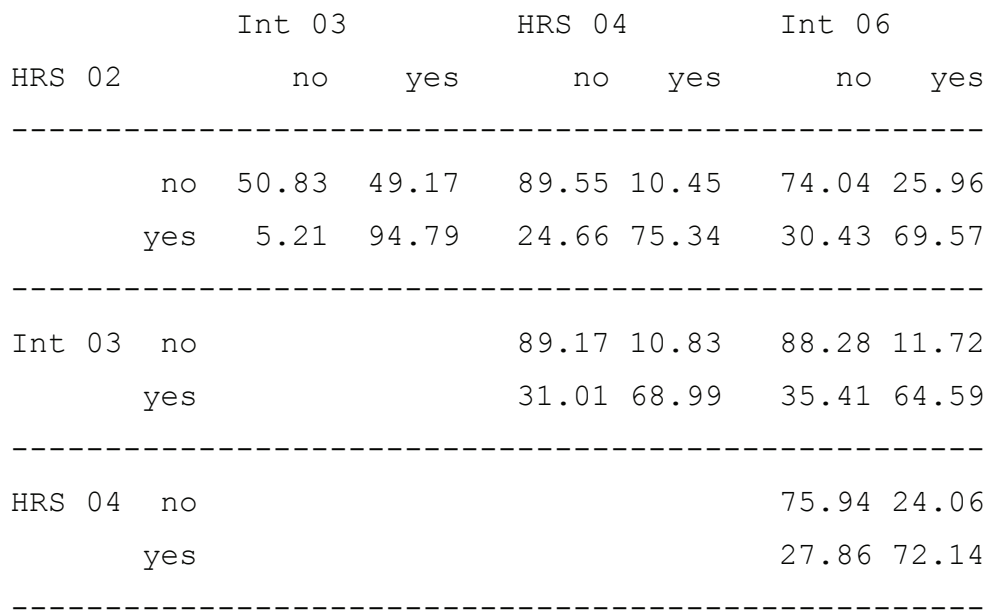

Note: Transition rates in $\%$

Table 4 controls for these selection effects by considering the transition rates in the balanced sample of respondents who participated in all four surveys. It confirms that HRS Internet 2003 is different from the other surveys. While numbers of transitions in and out of ownership are roughly similar for transitions among HRS 2002, HRS 2004 and HRS Internet 2006, this is not the case for transitions involving HRS Internet 2003. For 2003, transition rates into ownership are relatively large, and transition rates out of ownership are large as well. All this could be explained from reporting errors in HRS Internet 2003, if many non-owners report ownership. Such a reporting error does not occur in HRS Internet 2006.

Table 5 reports the answers to the HRS Internet 2006 question: "Considering the total value of your stocks and stock mutual funds, do you think it is more than, less than, or about the same as at the time of the HRS interview in 2004?” (see Section 2), asked to all respondents who reported (in the HRS Internet 2006 interview) they owned stocks. 
Table 4. Transitions in Stock Ownership - Balanced Panel

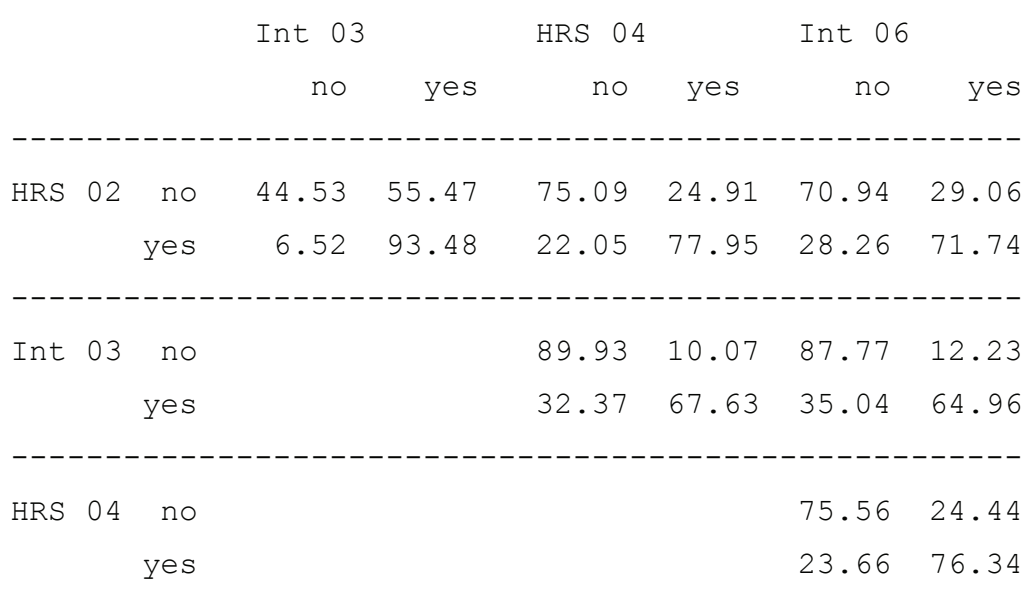

Note: Transition rates in

Table 5. Reported changes in HRS Internet 2006 by ownership in 2004

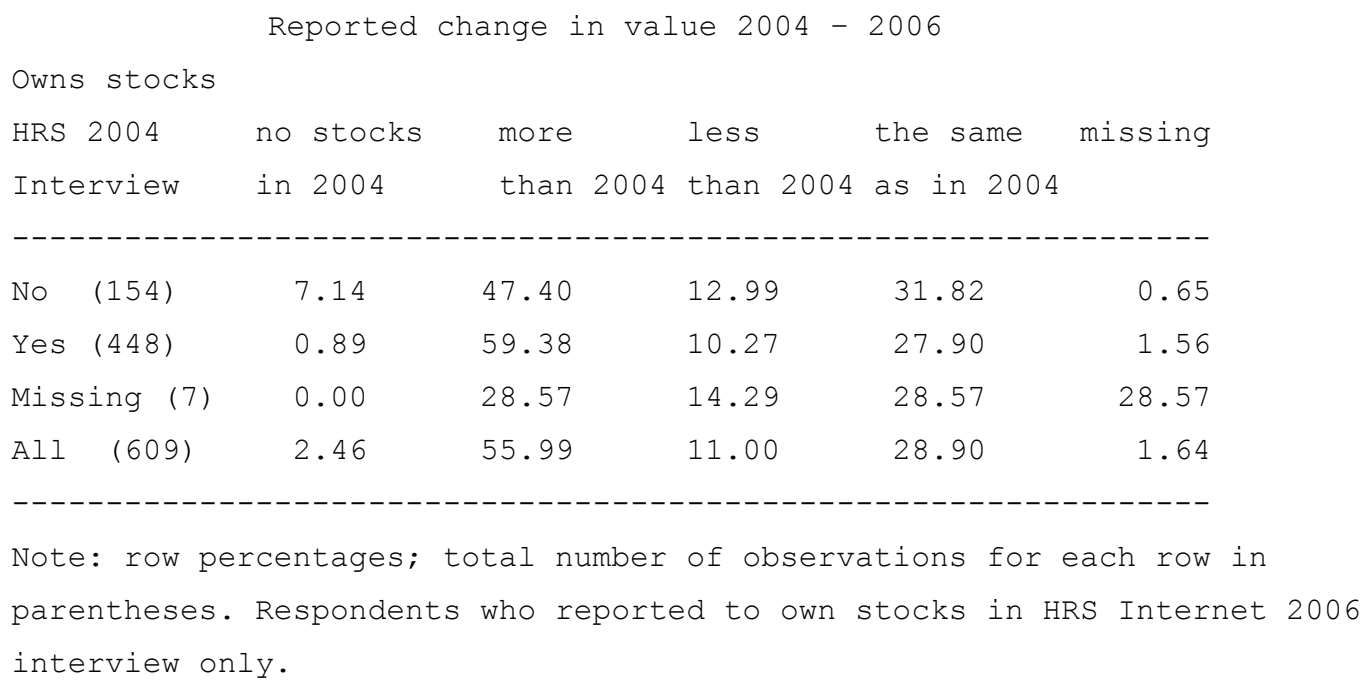

\begin{abstract}
Although there is a significant correlation between the answer to this question and stock ownership in 2004, the correlation is far from perfect. In particular, a large majority of the 154 respondents who in 2004 reported that they had no stocks (at that time) and in 2006 report that they have stocks, do not choose the answer "had no stocks at that time," which seems the obvious answer for these people. Almost $44 \%$ of these non-owners in 2004 and owners in 2006 indicated that the value of their stocks in 2006 was about the same as or even less than the value of their stocks in 2004.
\end{abstract}


Similarly, Table 6 reports the answers to the question "Did you buy or sell stocks or stock mutual funds since the HRS Interview in 2004?" (see Section 2). As expected, there is an association between the answers to this question and ownership reported in HRS 2004, though it is not very strong, and the p-value of the chi-square test of independence is 0.032. Again, inconsistencies are revealed - half of those who reported non-ownership in 2004 and ownership in 2006 said they bought no stocks or stock mutual funds in the mean time.

\section{Table 6. Reported Buying and Selling of Stocks since 2004, by HRS 2004 Stocks Ownership Status}

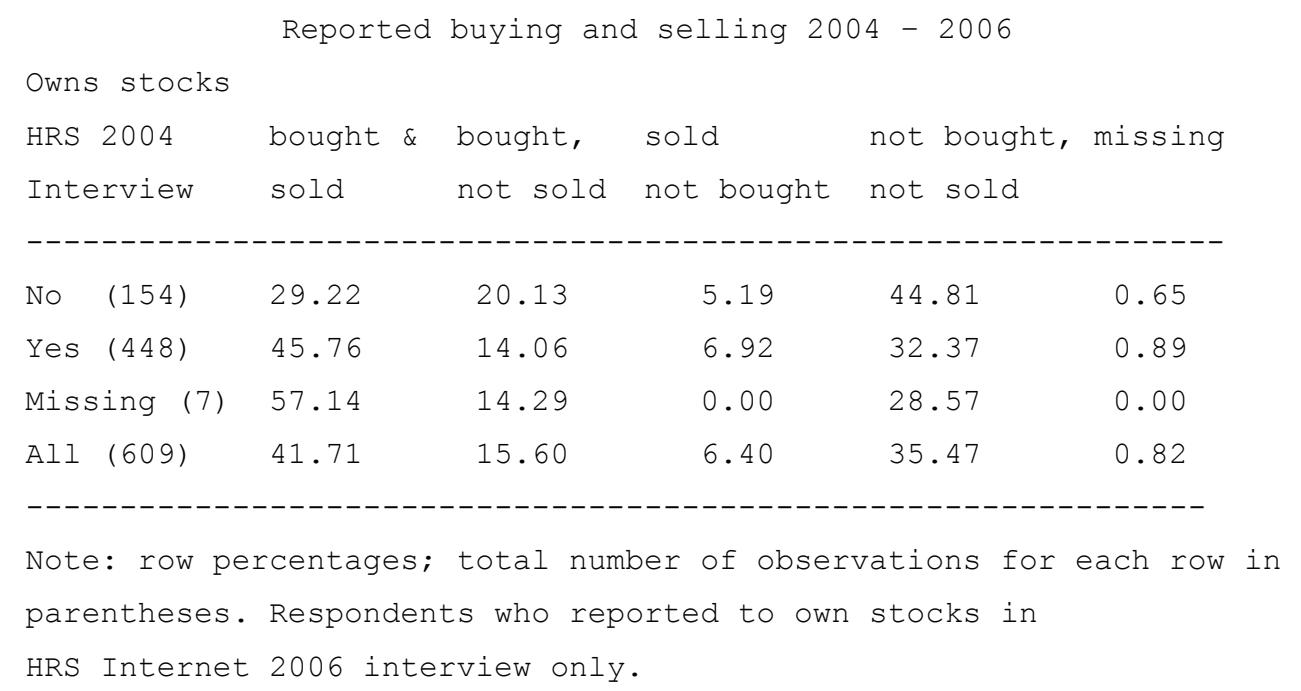

Table 7 shows that the answers to the two retrospective questions are associated in the expected way. For example, respondents who said they bought but did not sell often report that the value of their assets has increased. Those who reported they neither bought nor sold stocks or stock mutual funds, often report that the value of the amount held has remained about the same.

Tables 5, 6 and 7 suggest that reporting errors are common but there is no evidence that they are systematic. Perhaps the retrospective questions suffer from recall error, making the answers to them less accurate than those to the questions on current ownership. The 
tables provide no evidence that the HRS Internet 2006 answers are more or less reliable than the answers in the core HRS 2004 interview.

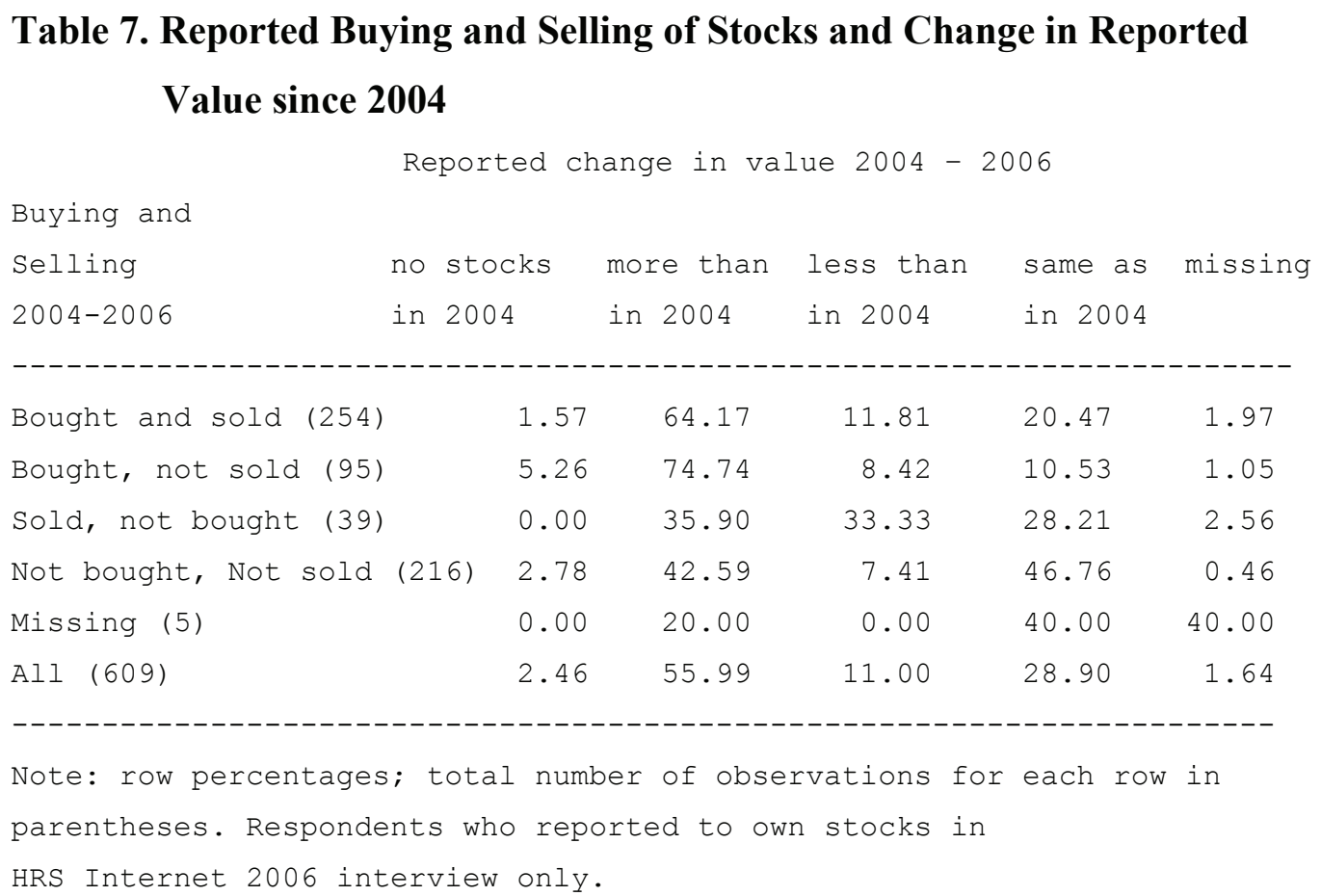

\section{Amounts Held}

In this section we consider the amounts held for each of the two types of assets of our interest, conditional on ownership of that type of asses. This follows the logic of the questionnaire (Section 2), where amount questions are only asked to respondents who have already answered the ownership question affirmatively. We only consider open ended answers and do not use the information provided in follow-up unfolding brackets by respondents who do not answer the open-ended question by giving an amount.

\section{Checking and Saving Accounts}

Table 8 presents the distribution of amounts invested in checking and saving accounts, excluding zeros (i.e., only for those who own the asset) and discarding missing values. 
We also discard the information in follow-up unfolding bracket questions and treat the bracket answers simply as missing open-ended answers. ${ }^{13}$

Table 8. Amounts on Checking and Saving Accounts All Respondents with Positive Amount

$\begin{array}{rrrrr}\text { Percentile HRS } & 2002 & \text { Int } 2003 & \text { HRS } 2004 & \text { Int } 2006 \\ 10 & 490 & 2000 & 300 & 1000 \\ 25 & 2000 & 8000 & 2000 & 3000 \\ 50 & 8000 & 30000 & 8000 & 10000 \\ 75 & 26000 & 100000 & 25000 & 40000 \\ 90 & 75000 & 250000 & 70000 & 100000 \\ \text { Observ. } & 15437 & 1769 & 12579 & 939\end{array}$

Respondents with Checking and Saving Account in HRS Internet 2003

\begin{tabular}{|c|c|c|c|c|}
\hline Percentile & HRS 2002 & HRSI 2003 & HRS 2004 & HRSI 2006 \\
\hline 10 & 1400 & 2000 & 1500 & 1200 \\
\hline 25 & 4000 & 8000 & 4750 & 5000 \\
\hline 50 & 12000 & 30000 & 13000 & 15000 \\
\hline 75 & 35000 & 100000 & 39000 & 50000 \\
\hline 90 & 85000 & 250000 & 90000 & 100000 \\
\hline Observ. & 1958 & 1769 & 1656 & 468 \\
\hline
\end{tabular}

Respondents with Checking and Saving Account in HRS Internet 2006

\begin{tabular}{|c|c|c|c|c|}
\hline Percentile & HRS 2002 & HRSI 2003 & HRS 2004 & HRSI 2006 \\
\hline 10 & 1500 & 3000 & 1500 & 1000 \\
\hline 25 & 5000 & 10000 & 5000 & 3000 \\
\hline 50 & 12000 & 35000 & 13500 & 10000 \\
\hline 75 & 40000 & 100000 & 35000 & 40000 \\
\hline 90 & 90000 & 250000 & 80000 & 100000 \\
\hline Observ. & 888 & 480 & 956 & 939 \\
\hline
\end{tabular}

The first panel considers all respondents in the unbalanced panel. There is a large difference between HRS Internet 2003 and the other three surveys, with much higher

13 The existing literature suggests that item non-response is not random (e.g., Juster and Smith, 1997). Still, the numbers of missing values are similar in all surveys and there is no reason why the selection effect due to non-response should be very different across surveys. It therefore seems very unlikely that they have an effect on our comparisons or can explain the differences in distributions across surveys. 
amounts in the former. This could be due to selection. Panel 2 therefore only considers the HRS Internet 2003 respondents. This leads to higher amounts for the other three surveys also, but the gap between HRS Internet 2003 and the other three surveys remains very large.

The third panel of Table 8 shows that this issue is specific to HRS Internet 2003 and does not play a role in HRS Internet 2006: If we consider HRS Internet 2006 participants only, the amounts reported in 2006 are distributed similarly to those in the regular HRS surveys of 2002 and 2004. For this subsample also, the amounts reported in HRS Internet 2003 have a quite different distribution with much larger percentiles throughout.

Figure 1 confirms these findings. It compares the distribution of the amounts reported in 2002 and 2003 by those who reported to own a checking or saving account in HRS Internet 2003, as well as the distribution of the amounts reported in 2004 and 2006 of those who reported ownership in HRS Internet 2006. Thus selection on Internet access is controlled for in all four distributions (the figure essentially combines the second and third panel of Table 8). The salient feature of the figure is the deviating pattern for HRS Internet 2003.

Rank correlations between amounts in checking and saving accounts reported in different waves are presented in Table 9. All of these are significantly positive. The rank correlation between amounts reported in the two regular interviews is highest, followed by the correlation for the two Internet interviews. From this table, it is not apparent that the HRS Internet wave 1 data are systematically different from the other waves. The levels (as described in Table 8 and Figure 1) make it different, not the relative position of each household's amount. 
Fig. 1: Checking and saving - Internet samples

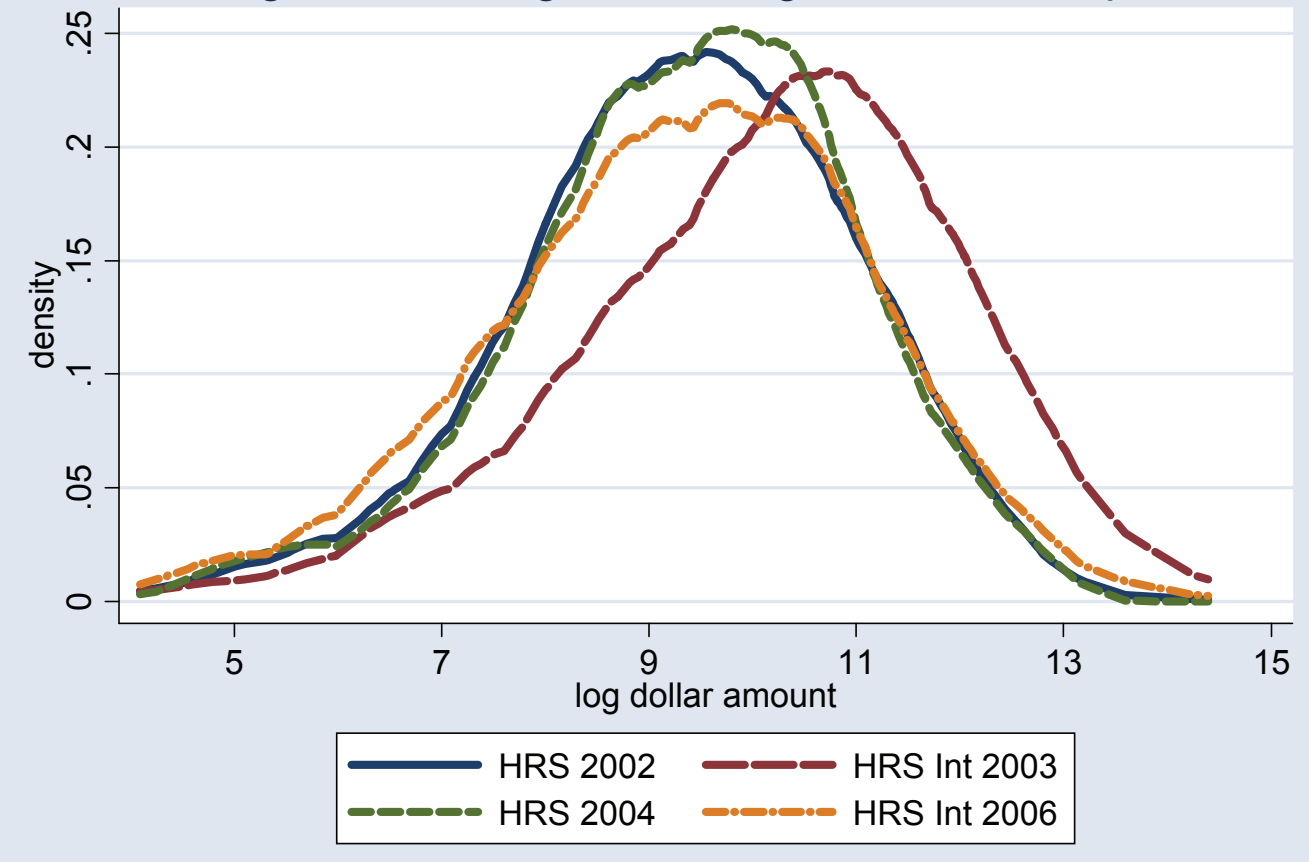

Table 9. Rank Correlations between Amounts in Checking and Saving Accounts

HRS Internet 2003 HRS 2004 HRS Internet 2006

\begin{tabular}{llll}
\hline HRS 2002 & 0.500 & 0.623 & 0.461 \\
HRS Internet 2003 & & 0.522 & 0.471 \\
HRS 2004 & & & 0.559 \\
\hline
\end{tabular}

In HRS Internet 2006 respondents with a checking or saving account were asked "Do you have more or less money in (all) your checking or saving accounts or money market funds than at the time of the HRS interview in 2004?" (see Section 2). About 43\% of respondents with a checking or saving account in HRS Internet 2006 say the amount on their account(s) increased. The table shows that, accordingly, the median difference between the amounts reported in HRS Internet 2006 and HRS 2004 is positive, but there is also a substantial number of households for which this difference is negative. This is 
evidence of reporting errors, either due to recall error or in current amounts held. About $37 \%$ report the value is about the same at the times of the two interviews. Indeed, the median change in reported amounts is close to zero, but the variation around that median is huge. As before we can conclude that, although there is a significant association between the retrospective report of the change and the change measured as the difference in amounts held reported at the two points in time, at least one of these measures must be rather noisy. ${ }^{14}$

\section{Table 10. Changes in Amounts in Checking and Saving Accounts}

\begin{tabular}{|c|c|c|c|c|c|c|}
\hline \multirow{2}{*}{$\begin{array}{l}\text { Retrospective } \\
\text { Question }\end{array}$} & & \multicolumn{5}{|c|}{ Percentiles of the Difference between reported } \\
\hline & & levels in & HRS Interne & 2006 and & HRS 2 & \\
\hline & Observ. & 10 & 25 & 50 & 75 & 90 \\
\hline No account in 2004 & 4 & -8500 & -8215 & -3465 & 1675 & 2350 \\
\hline More than in 2004 & 344 & -35000 & -7000 & 3000 & 27000 & 71900 \\
\hline Less than in 2004 & 148 & -57000 & -21750 & -3000 & 2600 & 31000 \\
\hline About the same & 332 & -23000 & -7000 & -500 & 2000 & 24000 \\
\hline All & 828 & -33500 & -9950 & 0 & 10000 & 48000 \\
\hline
\end{tabular}

Note: Households with checking and saving accounts in HRS Internet 2006

\section{Stocks and Stock Mutual Funds}

Table 11 is similar to Table 8, but now for stocks and stock mutual funds. Comparing the first panel with the other two panels shows that the people who participated in one of the Internet interviews and had stocks then typically hold higher amounts in the other waves as well. Once selection into Internet access is corrected for, the differences between the four waves are not that large. The distribution in HRS Internet 2003 is not different from the other distributions as for checking and saving accounts. Still, HRS Internet 2003 gives the highest amounts. Since the other Internet interview gives the lowest amounts, this is unlikely to be due to a pure mode effect, but more suggestive of a context effect.

${ }^{14}$ After the question whether the amount held is more or less than in 2004, there was a follow-up question for those who answer "more" or "less" on the amount of change. This question is not used here. 
Table 11. Amounts in Stocks and Stock Mutual Funds

All Respondents with Positive Amount

$\begin{array}{rrrrr}\text { Percentile } & \text { HRS } 2002 & \text { Int } 2003 & \text { HRS } 2004 & \text { Int } 2006 \\ 10 & 2500 & 3000 & 3000 & 2000 \\ 25 & 12000 & 23000 & 12000 & 12000 \\ 50 & 50000 & 90000 & 50000 & 50000 \\ 75 & 200000 & 250000 & 200000 & 175000 \\ 90 & 400000 & 600000 & 500000 & 400000 \\ \text { Observ. } & 5798 & 1262 & 4063 & 434\end{array}$

Respondents who report that they own Stocks or Stock

Mutual Funds in HRS Internet 2003

$\begin{array}{rrrrr}\text { Percentile } & \text { HRS } 2002 & \text { Int } 2003 & \text { HRS } 2004 & \text { Int } 2006 \\ 10 & 5000 & 3000 & 4600 & 3000 \\ 25 & 20000 & 23000 & 20000 & 15000 \\ 50 & 75000 & 90000 & 80000 & 70000 \\ 75 & 200000 & 250000 & 249000 & 200000 \\ 90 & 500000 & 600000 & 500000 & 400000 \\ \text { Observ. } & 1033 & 1262 & 807 & 223\end{array}$

Respondents who report that they own Stocks or Stock

Mutual Funds in HRS Internet 2006

$\begin{array}{rrrrr}\text { Percentile } & \text { HRS } 2002 & \text { Int } 2003 & \text { HRS } 2004 & \text { Int } 2006 \\ 10 & 5000 & 10000 & 5000 & 2000 \\ 25 & 18000 & 30000 & 24000 & 12000 \\ 50 & 85000 & 100000 & 100000 & 50000 \\ 75 & 250000 & 300000 & 250000 & 175000 \\ 90 & 600000 & 700000 & 500000 & 400000 \\ \text { Observ. } & 366 & 233 & 349 & 434\end{array}$

Figure 2, constructed in a similar way as Figure 1, compares the distribution of the positive amounts in stocks and stock mutual funds reported in 2002 and 2003 by those who reported to own the asset in HRS Internet 2003, as well as the distribution of the positive amounts reported in 2004 and 2006 of those who reported ownership in HRS 
Internet 2006. Thus selection on Internet access is controlled for in all four distributions. The figure shows some differences across the four distributions, confirming Table 11, and also confirms that, controlling for selection, the distribution of amounts in stocks and stock mutual funds in HRS Internet 2003 is not very different from the distribution of this asset in the other three surveys.

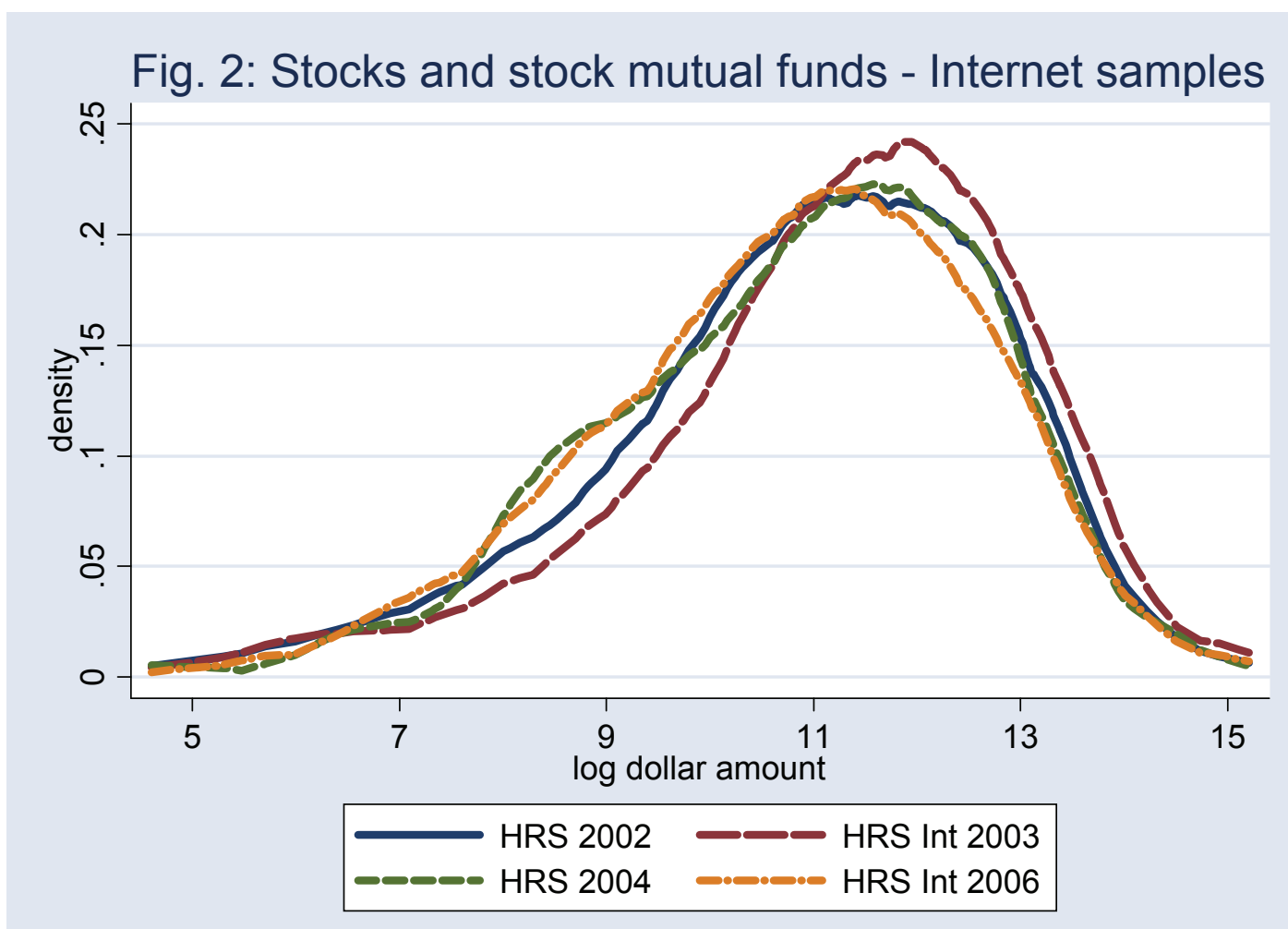

Table 12 gives the rank correlation coefficients for the positive amounts for each pair of waves. There is some similarity with Table 9 in the sense that the highest correlation is between the two core HRS interviews. In this case, the lowest correlation is between the two Internet interviews.

Table 13 is the analog of Table 10 for stocks and stock mutual funds. For those who report in 2006 that the value of their stocks and stock mutual funds increased, the median difference between the reported amounts held in 2004 and 2006 is indeed positive. Still, for $37 \%$ of this group, the difference in reported amounts is negative. For those who report in 2006 that the total value has fallen, the median difference in reported amounts is 
zero; for those who report in 2006 that the total value of their stocks and stock mutual funds remained about the same, the median difference between amounts reported in 2006 and 2004 is $\$ 1000$. The ordering of the median differences is as expected, but the large variation at the household level is a strong indication of reporting errors in either the retrospective questions or the reports of current values (or both).

Table 12. Rank Correlations between Amounts in Stocks and Stock Mutual Funds HRS Internet 2003 HRS 2004 HRS Internet 2006

\begin{tabular}{llll}
\hline HRS 2002 & 0.609 & 0.734 & 0.615
\end{tabular}

HRS Internet $2003 \quad 0.649 \quad 0.557$

HRS 2004

0.654

Table 13. Changes in Total Values of Stocks and Stock Mutual Funds

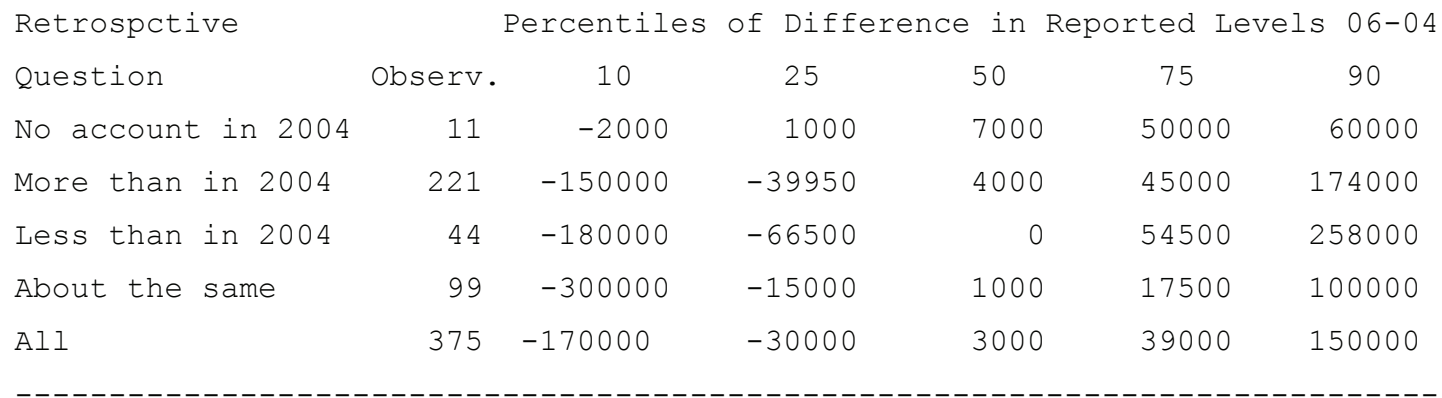

Note: Households with stocks and stock mutual funds in HRS Internet 2006

\section{Regression Models for Ownership and Amounts Held}

In this section we explain ownership and amounts held given ownership from background variables relating to gender, household composition, age and education. We consider models for each wave separately and random effects models that assume slope parameters are constant across waves, with time dummies to capture differences across waves. 
The goal of these regressions is to investigate whether the determinants of ownership and amounts held vary across waves (which can be analyzed using separate regressions for each of the four panel waves) and whether the across waves differences in ownership rates and amounts held that were found in the previous sections remain if background characteristics are controlled for (which can be analyzed using panel data models). We know that there are strong selection effects - the households with Internet access more often hold assets and hold higher amounts than those without Internet access. We do not analyze the selection effects here but control for them by only including households who participated in at least one of the Internet interviews in the regressions.

\section{Table 14. Ownership of Checking and Saving Accounts - Probits by Wave}

\begin{tabular}{|c|c|c|c|c|c|c|c|c|}
\hline & \multicolumn{2}{|c|}{ HRS 02} & \multicolumn{2}{|c|}{ HRS Int 03} & \multicolumn{2}{|l|}{ HRS 04} & \multicolumn{2}{|c|}{ HRS Int 06} \\
\hline & Coef. & $t-v a l$ & Coef. & $t-v a l$ & Coef. & $t-v a l$ & Coef. & t-val \\
\hline byear & -0.000 & -0.06 & -0.015 & -1.62 & -0.005 & -0.77 & -0.008 & -0.97 \\
\hline gend & -0.001 & -0.01 & -0.015 & -0.11 & -0.055 & -0.56 & -0.126 & -1.08 \\
\hline nonwh & -0.228 & $-1 \cdot 34$ & -0.115 & -0.47 & -0.296 & -1.88 & -0.049 & -0.26 \\
\hline hispan & -0.282 & -1.06 & -0.318 & -0.89 & -0.607 & -2.93 & -0.345 & -1.31 \\
\hline edmed & -0.206 & -0.85 & 0.396 & 1.66 & -0.146 & -0.59 & 0.243 & 0.93 \\
\hline edhigh & -0.058 & -0.25 & 0.617 & 2.72 & -0.019 & -0.08 & 0.536 & 2.09 \\
\hline marr & 0.032 & 0.28 & 0.318 & 2.24 & 0.146 & 1.34 & 0.193 & 1.51 \\
\hline work & -0.143 & -1.19 & 0.014 & 0.08 & -0.048 & -0.40 & 0.097 & 0.67 \\
\hline retir & -0.101 & -0.82 & -0.164 & -0.92 & -0.141 & -1.09 & 0.217 & 1.34 \\
\hline constant & 1.900 & 5.00 & 1.992 & 3.99 & 2.173 & 5.44 & 1.300 & 2.68 \\
\hline
\end{tabular}

Notes: Respondents who participated in at least one Internet interview.

Dependent variable: 1 if household reports ownership, 0 if it reports nonownership. Don't know and refuse answers excluded.

Explanatory variables: byear: year of birth; gend: dummy for females; nonwh: dummy non-white; hispan: dummy Hispanic; edmed, edhig: dummies for intermediate and higher education; marr: dummy married; work: dummy working for pay; retir: dummy for being retired.

Table 14 presents probit results for ownership of checking and saving accounts for each wave separately. Few variables are significant, which may not be too surprising since ownership rates among households with Internet access are well over 90\% in all waves 
(Table 1) so that there is not very much to explain. Still, there seem to be some substantial differences across waves. The high educated are more likely to have a checking and saving account in the Internet interviews (2003 and 2006), but not in the (2002 and 2004) core HRS interviews. Hispanics are particularly unlikely to have a checking or savings account in HRS 2004.

Table 15 gives the results for ownership of stocks and stock mutual funds (cf. Table 2). The pattern is quite consistent across waves for most variables. Higher education and being married make stock ownership more likely, wile non-whites and Hispanics are less likely to own stocks than non-Hispanic whites. The effect of labor force status variables varies but is never significant. The main difference across waves seems to be the effect of birth year (or age) - it is significantly negative in all waves except the HRS Internet interview in 2003, where it is negative but small and insignificant. This suggests that the very high ownership rates reported in this interview are mainly an issue for the younger age groups.

Table 15. Ownership of Stocks and Stock Mutual Funds - Probits by Wave

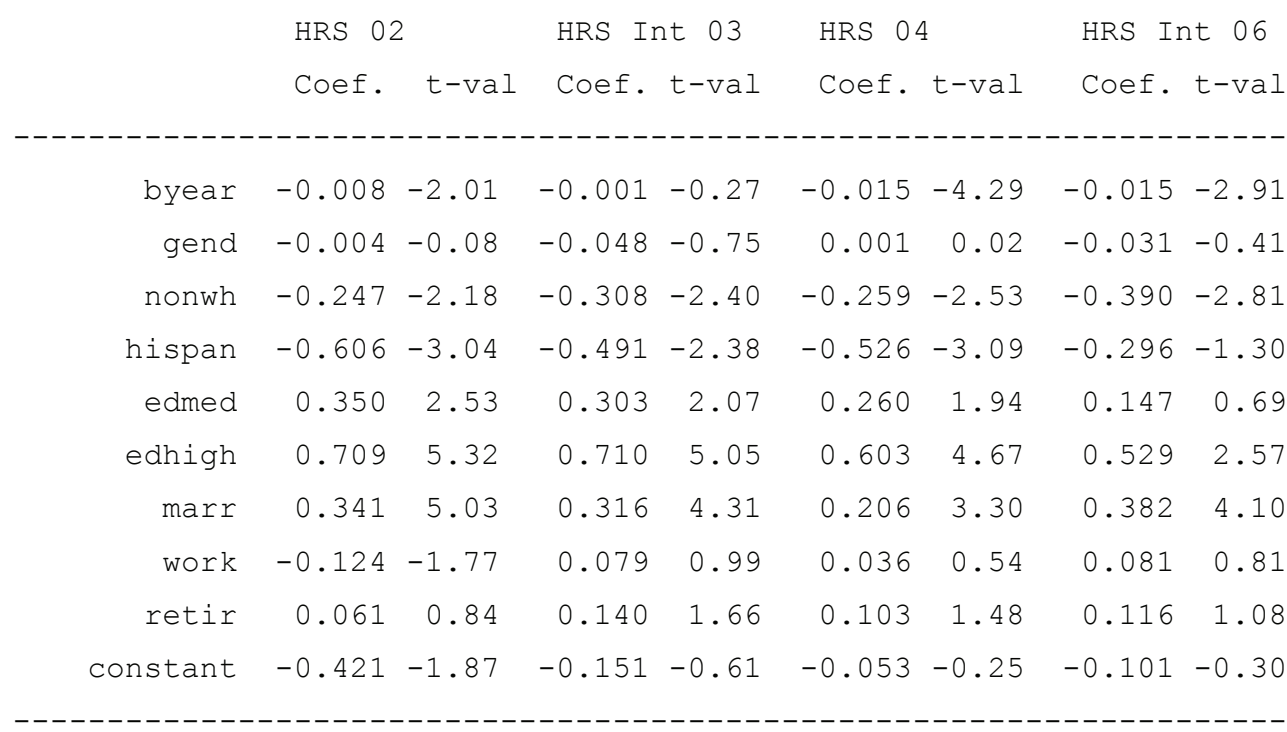

Notes: See Table 14. 
Table 16 presents random effects probit models for both assets, imposing equal slope coefficients across waves. Because observations from the four panel waves are pooled now, significance levels tend to be higher than in Tables 14 and 15. Non-whites and Hispanics are less likely to hold both types of assets, particularly stocks. Younger cohorts are less likely to hold stocks. Education and being married have a positive effect on holding stocks but a small and insignificant effect on holding checking or saving accounts. Labor force status plays no significant role for either type of assets. Random effects are significant in both cases, but more so for stocks than for checking and saving accounts, implying strong persistence in stock ownership. ${ }^{15}$

The parameters of main interest in Table 16 are the coefficients on the time dummies. Keeping background variables constant, we find significant differences in ownership rates of checking and saving accounts across waves. In particular, it seems ownership is less likely in HRS 2002 and HRS Internet 2006 than in the waves in between (HRS Internet 2003 and HRS 2004). We do not have a good explanation for this finding; it does not seem to be related to interviewing mode and may reflect a macro-economic time effect.

As expected given the results in Section 3, the most salient feature is the huge coefficient on the time dummy for 2003 in the ownership of stocks equation. This corresponds to the descriptive statistics (cf. Table 2) - controlling for background variables does not change the conclusion that ownership of stocks and stock mutual funds among the subpopulation with Internet access is much higher according to the reports in HRS Internet 2003 than in the other three surveys. The marginal effect (Keeping everything else constant at the sample mean, and setting the individual effect to its mean of zero) is about 40 percentage points.

\footnotetext{
${ }^{15}$ Unobserved and observed heterogeneity are the only sources of persistence incorporated in the model. More sophisticated models also allow for state dependence: a causal effect of ownership in one wave on ownership in the next wave. See, e.g., Alessie, Hochguertel and van Soest (2002).
} 
Table 16. Asset Ownership - Random Effects Probits

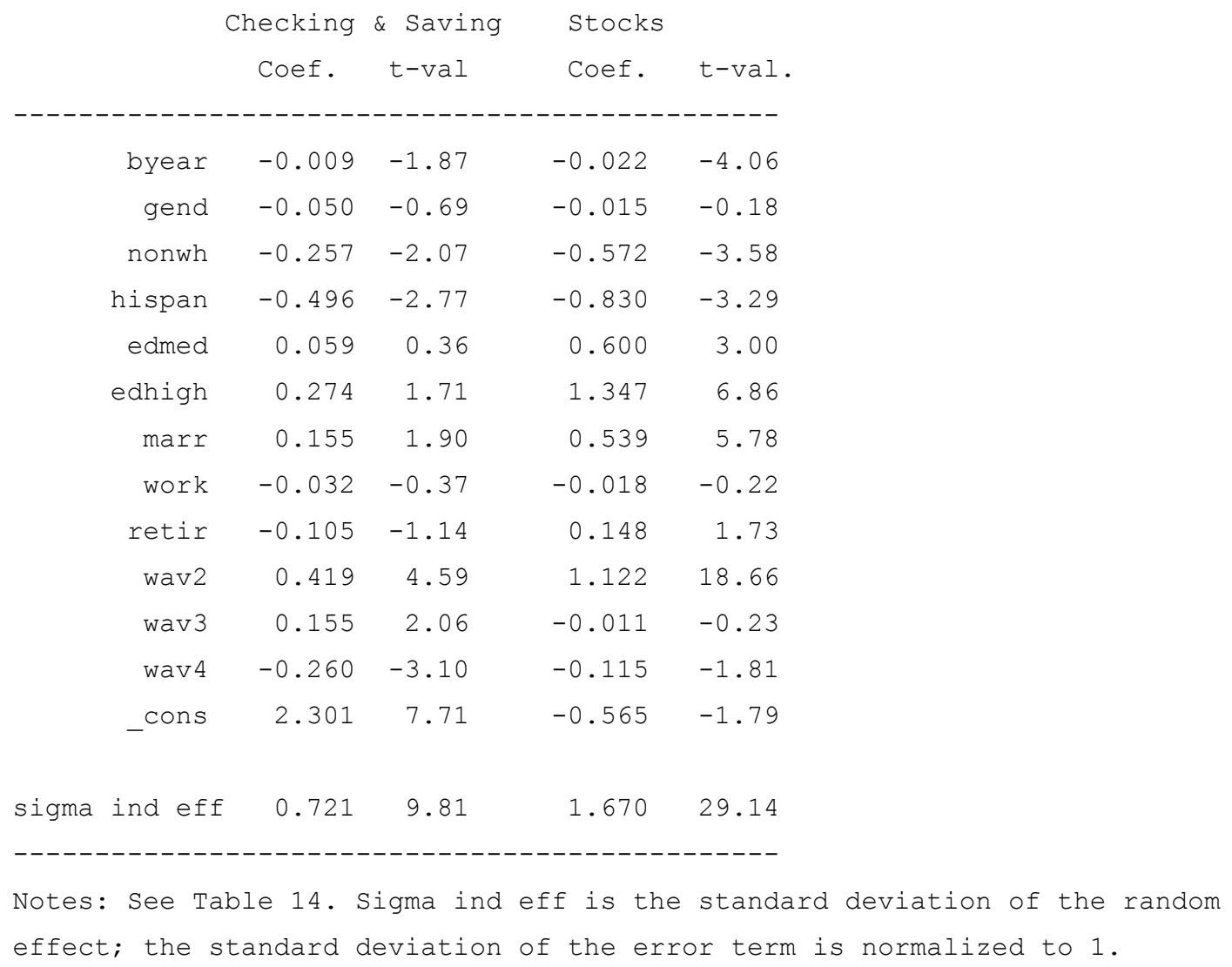

Table 17 presents the OLS estimates for a linear regression model explaining the log of the amount on checking and saving accounts for each wave from the same background variables as before. This is conditional on Internet access, ownership, and reporting a positive amount. The effects of age and education are stable over the four survey waves. Gender is always insignificant. Nonwhites hold lower amounts than whites and Hispanics hold less than non-Hispanics, though this effect is often insignificant. There seems to be nothing in this table that would suggest that specific socio-economic groups are responsible for the much higher amounts reported in HRS Internet 2003. Moreover, the amount of noise is very similar in the two Internet surveys. 
Table 17. Log Amounts in Checking and Saving Accounts - OLS by Wave

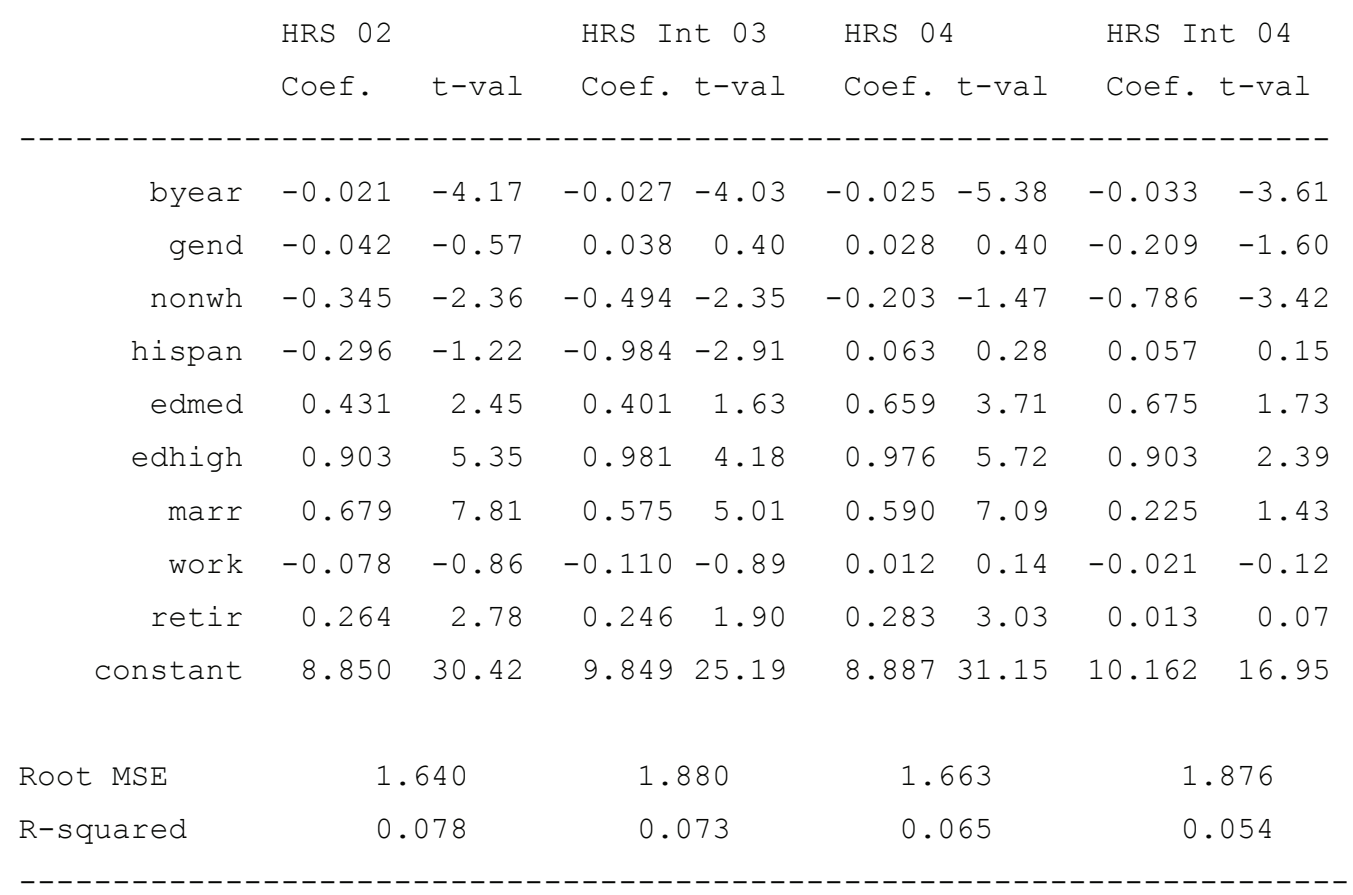

Notes: Respondents who participated in at least one Internet interview, report that they own a checking or savings account and report a positive amount. See Table 14 for definitions of explanatory variables.

Table 18 presents the same regressions for stocks and stock mutual funds. There are substantial differences across waves, particularly between the HRS Internet 2006 survey and the other three surveys. For example, the (positive) effect of education has disappeared completely. The same applies to marital status and labor force position. The 2006 Internet wave gives the lowest R squared and the highest estimate of the noise level (the mean squared error, MSE). Therefore, unlike in the previous results, it seems that when amounts in stocks and stock mutual funds are concerned, the 2006 Internet survey is more of an outlier that the 2003 Internet survey. 
Table 18. Log Amounts in Stocks and Stock Mutual Funds - OLS by Wave

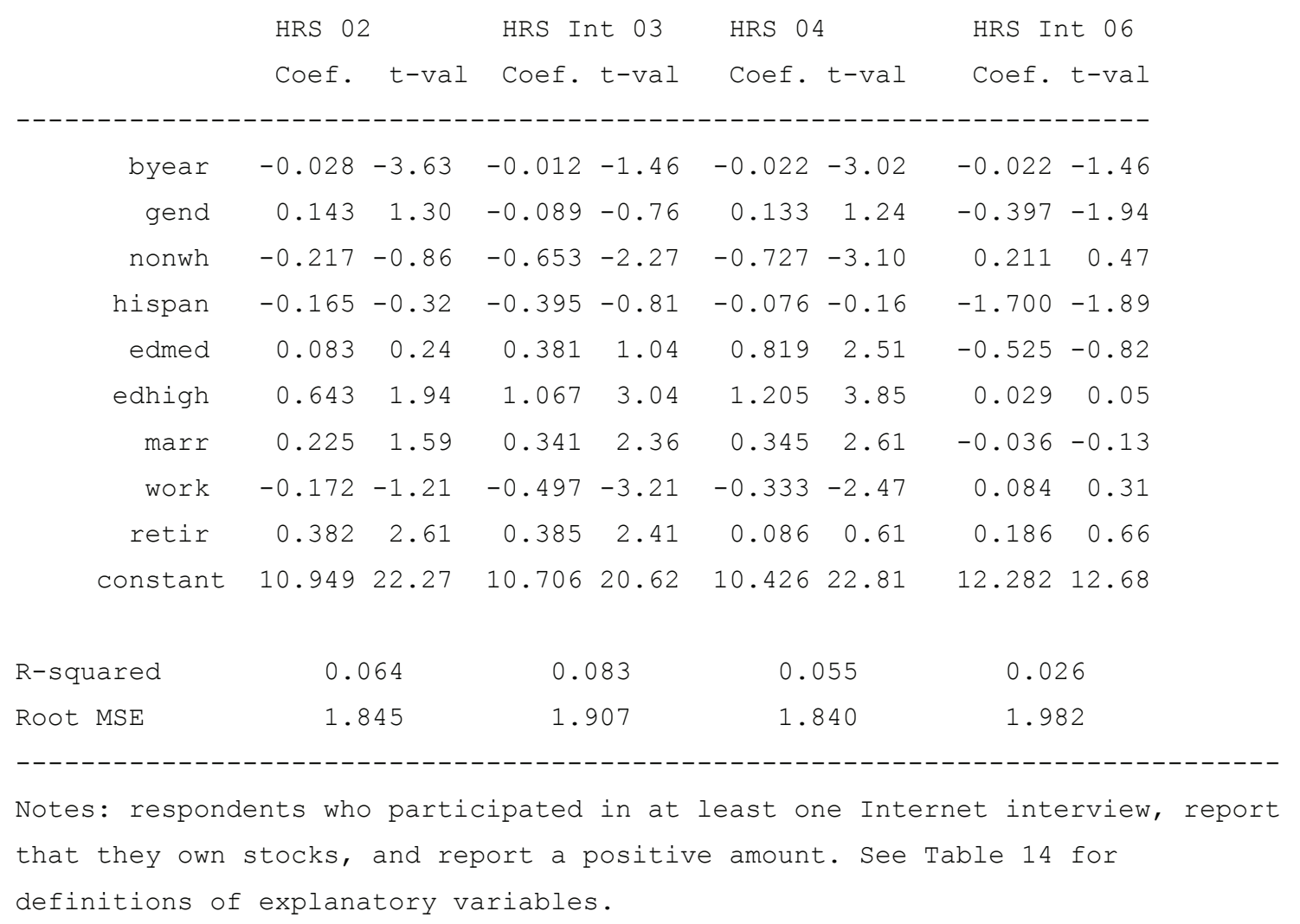

Table 19 presents the estimates of random effects models for the log of the amounts held of both types of assets. On average over the four waves, younger households and nonwhites hold lower amounts than others. The higher educated hold higher amounts. Retired (heads of) household(s) hold higher amounts also. The estimated standard deviations of individual effects and error terms indicate high persistence of amounts held, with more than half of the unsystematic variation ascribed to the random effects.

The main parameters of interest are the time dummies - They clearly confirm the unusually high amounts on checking and saving accounts reported in HRS Internet 2003, keeping constant everything else. The amounts are 75 to $90 \%$ higher than in the other surveys. The amounts invested in stocks are also quite high in the 2003 Internet interview but the difference is not as extreme as for checking and saving accounts. 
Table 19. Asset Amounts - Random Effects Models

\begin{tabular}{|c|c|c|c|c|c|c|}
\hline & & hec & & \& Saving & Stc & $\mathrm{cks}$ \\
\hline & & & & t-val. & Coef. & t-val. \\
\hline & byear & -0 & & -7.15 & -0.023 & -4.26 \\
\hline & gend & -0 & 13 & -0.21 & 0.026 & 0.31 \\
\hline & nonwh & -0 & 99 & -3.42 & -0.482 & -2.61 \\
\hline & hispan & -0 & & -1.46 & -0.197 & -0.61 \\
\hline & edmed & & & 4.17 & 0.368 & 1.49 \\
\hline & edhigh & & 28 & 7.08 & 0.845 & 3.55 \\
\hline & $\operatorname{marr}$ & & 14 & 7.68 & 0.307 & 3.11 \\
\hline & work & -0 & 24 & -0.39 & -0.188 & -2.18 \\
\hline & retir & & 51 & 2.42 & 0.233 & 2.69 \\
\hline & Int 2003 & & 52 & 21.24 & 0.386 & 7.34 \\
\hline & HRS 2004 & & 10 & 3.05 & 0.115 & 2.28 \\
\hline & Int 2006 & & 81 & 1.54 & -0.116 & -1.46 \\
\hline & constant & & 46 & 39.48 & 10.666 & 31.14 \\
\hline sigma & a ind. ef & ct & 1 & 250 & 1.4 & \\
\hline sigma & a error & & 1 & 230 & 1.2 & \\
\hline
\end{tabular}

Notes: Respondents who participated in at least one Internet interview, report that they own the asset, and report a positive amount. See Table 14 for definitions of explanatory variables.

\section{Conclusions}

This paper compares two types of assets in US household portfolios, checking and saving accounts and stocks and stock mutual funds held in two regular HRS interviews and two HRS Internet interviews. The design of the Internet surveys makes it possible to disentangle selection effects from mode or context effects. The main conclusions are threefold. First, we find large selection effects: respondents with Internet access more often own stocks and stock mutual funds. They also hold higher amounts of both types of assets, conditional on ownership. Second, controlling for these selection effects, we find some salient differences between HRS Internet 2003 and the other surveys: ownership of stocks and stock mutual funds is much larger, and the amounts held in checking and saving accounts are much larger. These features are specific to HRS Internet 2003 and 
are not shared by HRS Internet 2006. They are not only apparent from the descriptive statistics, but also from regression models, when background variables are kept constant. Since they are not shared by the other Internet survey, we interpret them as effects of context and question wording rather than as pure mode effects. Third, retrospective questions on changes since the previous interview give answers associated with the change constructed from ownership and amounts held in the two interviews, but the association is far from perfect and implies many inconsistencies in either the reported changes or the reported asset levels (or both).

What does this imply for the future of Internet or mixed-mode surveys? First, the similarity of HRS Internet 2006 and the two core HRS surveys suggests that pure mode effects do not play a major role so that changing the interview mode from telephone or face-to-face to Internet does not necessarily lead to comparability problems of subsamples interviewed with different modes. On the other hand, the large differences between HRS Internet 2003 and the core interviews as well as HRS Internet 2006 lead to the conclusion that even for seemingly clear and objective questions such as the household portfolio questions that we have analyzed, careful question wordings given the question context is crucial. This is not just a matter of using identical question wordings in different survey modes. The question wording must be adjusted to the context. In our case the difference in preceding questions between the HRS core interviews and Internet 2003 appears to have caused the observed differences. Once we explicitly excluded certain asset categories in the Internet 2006 questionnaire (the categories that in the core interviews are asked in preceding questions), did the differences between Internet and HRS core interviews disappear.

It confirms a finding in much of the literature on this topic (e.g., Dillman and Christian, 2005): context and question wording are crucial and deserve more thought and attention than they usually get, particularly since they often change as a consequence of changing interview mode. With carefully designed questionnaires, pure mode effects can be avoided. 


\section{References}

Alessie, R., S. Hochguertel and A. van Soest (2002), Household portfolios in the Netherlands, in L. Guiso, M. Haliassos and T. Jappelli (eds.), Household Portfolios, MIT Press, Cambridge Mass., 341-388.

Berrens, R.P., A.K. Bohara, H. Jenkins-Smith, C. Silva and D.L. Weimer (2003), The advent of Internet surveys for political research: a comparison of telephone and Internet samples, Political Analysis, 11(1), 1-22.

Best, S.J., B. Krueger, C. Hubbard and A. Smith (2001), An assessment of the generalizability of Internet surveys, Social Science Computer Review, 19(2), 131-145.

Christian, L.M. and D. Dillman (2004), The influence of graphical and symbolic language manipulation on responses to self-administered surveys, Public Opinion Quarterly, 68(1), 58-81.

Couper, M.P., A. Kapteyn , M. Schonlau, and J. Winter (2007), Noncoverage and nonresponse in an Internet survey, Sociological Methods and Research, 36(1), 131-148.

Denscombe, M. (2006), Web-based questionnaires and the Mode Effect: an evaluation based on completion rates and data contents of near-identical questionnaires delivered in different modes, Social Science Computer Review, 24(2), 246-254.

Dillman, D.R. and L.M. Christian (2005), Survey mode as a source of instability in responses across surveys, Field Methods, 17(1), 30-52.

Fricker, R.D. and M. Schonlau (2002), Advantages and disadvantages of Internet research surveys: evidence from the literature, Field Methods, 14(4), 347-367.

Guiso, L., M. Haliassos and T. Jappelli (2002), Household Portfolios, MIT Press, Cambridge MA. 
Juster, T., and J.P. Smith (1997), Improving the quality of Economic data: Lessons from the HRS and AHEAD, Journal of the American Statistical Association, 92, 1268- 1278.

Schonlau, M., B.J. Asch and C. Du (2003), Web surveys as part of a mixed-mode strategy for populations that cannot be contacted by e-mail, Social Science Computer Review, 21(2), 218-222.

Schonlau, M., A. van Soest, A. Kapteyn and M. Couper (2009), Selection bias in Web surveys and the use of propensity scores, Sociological Methods and Research 37, 291318.

Schwarz, N. (1996), Cognition and communication judgmental biases, research methods, and the logic of conversation, Lawrence Erlbaum, Mahwah, NJ. 